\title{
The Teaching Reform of China's Higher Vocational Education Based on Core Vocational Ability Training
}

\author{
WANG Peng \\ Foreign languages department \\ Shijiazhuang Institute of Railway Technology Shijiazhuang \\ Hebei P.R.China \\ e-mail: hbwangpeng@yahoo.com.cn
}

\author{
JIANG Xi-xing \\ Foreign languages department \\ Shijiazhuang Institute of Railway Technology Shijiazhuang \\ Hebei P.R.China \\ e-mail: xixingjiang@yahoo.com.cn
}

\begin{abstract}
Core vocational ability raising can make the students have the superiority in the vocational competitive power and the adaptive faculty, but the core vocational ability training also has great deficiency in the higher vocational education practice. Discussion the core vocational ability training of vocational college forms intercommunity, skills dominant, development, diversity, etc. Thereby, makes a useful exploration for Chinese high vocational education.
\end{abstract}

Keyword-core vocational ability; vocational college; student; training

\section{INTRODUCTION}

The "core" of the core vocational ability is the common principle of subject knowledge, and it is the curriculum content can be transferred. "Ability" is the skills of the vocational education, and it is the automation action or the applied skill from practice. ${ }^{[1]}$

In order to train the core vocational ability, college and teacher should pay attention to the flowing four points:

Firstly, teacher should refine the vocational commonality in teaching content.

Secondly, teacher should highlight the skills dominant in teaching method.

Thirdly, teacher should focus on the development in teaching effect.

Finally, teacher should make the curriculum become diverse.

People with the core vocational ability have a strong environmental adaptability, career development, innovative thinking, mood-controlling and learning autonomy. So the higher vocational college must take the training of core vocational ability seriously. ${ }^{[2]}$

\section{THE FACED PROBLEMS IN THE CORE VOCATIONAL ABILITY TRAINING}

\section{A. The Teaching Content Lacks Vocational Commonality}

The traditional theory of vocational education tends to believe that vocational education must train person for specific post, so that person is able to immediately achieve task when he or she has finished the vocational education. But as a higher vocational education, it is not enough that students only have the knowledge and skills of certain task. That personnel training concept is too narrow. ${ }^{[3]}$ Taking tourism major for example, the students' primary employment unit is hotel or travel agency. There may be a lot of limitations in work if they only have the knowledge and skills about hotel or travel agency. So in order to make the students have a strong employment competitiveness and development potential, it is necessary to make them have some knowledge and skills of occupational commonality. They can adapt to the new work requirements and the dynamic environment through continuous learning and practice in future.

Nowadays, it is not enough thorough and meticulous to find the occupational commonality of teaching contents, more teaching contents also confine to the training of certain vocational knowledge and skills. In recent years, the teaching reform of some vocational colleges highlighted the training of knowledge and skills, but ignored the occupational commonality training. The vocational quality of students would be strengthened by this kind reform. But it is harmful for students to have the adaptation ability of dynamic environment. It can not meet the requirements of the modern vocational education development.

\section{B. The Teaching Method Lacks Skills Dominant}

In the traditional concept, acquisition of skills is an important symbol of vocational education success or not. The core vocational ability theory also pays great attention to the position of skills in the three elements of knowledge, skills and attitude. Highlighting the skills and practical ability is an important manifestation of the vocational education different from the regular higher education.

The training of students' vocational skills has been generally paid attention to it in teaching, but the training of problem-solving skills of students is still lack. Vocational skills are not equal to the problem-solving skills, vocational skills being individuality, but the problem-solving skills being common.

\section{The Teaching Effect Lacks Development}

Previous vocational education trains person according to post, all teaching activities focusing on the requirements of a specific post. The core vocational ability theory not only emphasizes qualified for specific post, but also pays attention to individual development and ability transferability. The core vocational ability makes person adapt the constantly changed environment of work. The value of knowledge and skill is not only the requirement of 
work, but also the requirement of sustainable development. It lays the foundation for lifelong education.

Nowadays, most assessments of the teaching effect are students' pass rate and excellent rates of examination, while the developmental assessment of teaching effect is rarely found. It is undeniable that the developmental assessment is to check the education impact on the students' development in future, so it is very difficult to do the judgment at present. Many colleges avoiding this problem in teaching practice.

\section{The Curriculum Lack Diversity}

In order to train students' core vocational ability, the content and form of curriculum must be diverse. Through that to achieve the all-round development of the individual ability, to stimulate the individual's interest in learning, to improve the practical ability, to cultivate the perfect personality, to develop good vocational habits, to train the spirit of solidarity and mutual assistance.

In teaching, due to the limited hardware conditions, many curriculums still take the form of teaching indoor. Although there are multimedia equipments and other modern teaching methods, the form is still single and lacks the necessary training conditions. Due to the reason of teachers' quantity and quality, the teaching of many vocational colleges is according to teachers rather than students. These cause many problems in teaching practice, such as curriculum lacks diversity, teaching methods are single, the effect is bad, etc.

\section{THE TRAINING OF CORE VOCATIONAL ABILITY FOR VOCATIONAL COLLEGE STUDENTS}

\section{A. Refining Vocational Commonality}

The reason we pay attention to the vocational commonality of knowledge and skills in the process of students' core vocational ability training can be summarized as the following three points: First, today in the integration of world economy, the talent can not depend on the unlimited extension of the single knowledge and skill alone, but depend on the cross use of diverse knowledge and skills. Second, the industry is in the unceasing development. The technique level of task continuously improves with the social development. Thus it needs a kind of commonality basic knowledge and basic skills as support. Third, a person will have different careers in his or her whole life, achieving careers conversion also need to have common knowledge and skills. ${ }^{[3]}$

Taking tourism major for example, the directions of their employment is high-star hotels and international travel agencies, so the vocational commonality should focus on communication, foreign language and other core vocational abilities, expanding the employment area to the whole services industry. Teacher should more use the cooperative learning methods in the usual teaching practice. The students should be divided to different groups. There should be division of work in one group and cooperation between different groups.
College should actively provide the opportunity to train students own communication skills and foreign language inside or outside schoolyard. In schoolyard, the students could service for various activities as volunteer. Out schoolyard, the students could train themselves through post practice in enterprises. Students could find the shortage of themselves from practice and work hard to meet the shortage during study in future.

\section{B. Highlighting Skills Dominant}

The social division of labor was highly specialized and immobilized in Fordist era. People was bound to a certain occupation or a fixed position for whole life long and worked a specific operation with a long time, but new social division of labor replaced the old social division system in Post-Fordist era. The new social division of labor shows the characteristics of liquidity, agility, creative. Person may have several or dozens of occupations in his or her life. ${ }^{[4]}$ The key factor to the conversion of different occupations is the core vocational ability. After short-term intensive training, acclimation and experience accumulation, person can successfully achieve occupation conversion. That is the reason why college should highlight skills dominant.

In recent years, the graduates' employment of different majors in vocational college is diversified. It is related to the students' job-choosing view change and the severe employment situation. Therefore in order to adapt to this situation, the higher vocational education ought to reflect the features of skills, especially core skills. Taking problem-solving ability and innovation ability for example, teachers need to combine with the present hot events to train students' problem-solving ability and innovation ability beside the contents in the teaching plan. Teacher ought to have the courage to break the routine for skills training. Teacher can make the present hot events as research topics which are completed by students themselves. Teacher only is responsible for the supervision and summary. This kind of training can achieve the purposes of training team consciousness, exercising communication ability, promoting the innovation level, etc.

\section{Focusing on Development}

Training the high-quality practical talents for society is the responsibility of higher vocational education. The developmental teaching effect largely dependents on core vocational ability training. The effect of teaching should not be confined to the future rather than the schoolyard. Higher vocational education saves strength and lays a good foundation for the future of the students, making the education effect shows in the sustainable development of students. The sustainable development is a kind of core vocational ability.

In the teaching, we need to focus on the knowledge and skills that is good for future development, besides the necessary vocational knowledge and skills. Taking digital application and information processing ability for example, 
many people believe that the tourism major belongs to a kind of typical liberal arts, so there are few science courses in talent training plan. The tourism major students are far behind the students of science in the operation ability and logical thinking ability.

It is very difficult to train the rigorous and pragmatic work style by this kind of talent training plan. In order to solve the problem college can arrange some elective courses in the talent training plan and prescribe the minimum credits. Teachers should not ignore the sustainable and developmental core vocational ability when train the vocational ability.

\section{Achieving Curriculum Diversity}

Education should teach students in accordance with their aptitude and interest, but Chinese higher vocational education still carry on the "cramming" teaching method from secondary education. Teacher orders students to do some enhanced learning and training in order to get some professional qualification certificates eventually. It does not train the core vocational ability of students, and produces strong resentment that affects the learning effect. In teaching, teacher should analyze the society needs and students' situation. College arranges a diverse curriculum through to research the connotation of the core vocational ability further. The curriculum system should include not only the knowledge and skills of specialized subject but also the training of core vocational ability, paying attention to training students' perfect personality, correct outlook on life, values and career. Generally speaking the diverse curriculum must include three parts: knowledge, skills and practice. Teacher should make the training of the core vocational ability into the three parts, and train the core vocational ability from different aspects with purpose and step.

Mr. Huang Yan-pei, the pioneer of Chinese vocational education, had summed up the significance of vocational education: personality development, making a living, social services, increasing productivity. ${ }^{[5]}$ In order to achieve the significance of vocational education, reflecting the superiority of higher vocational education, we should pay attention to the core vocational ability in refining vocational commonality, highlighting skills dominant, focusing on development, achieving curriculum diversity.

\section{REFERENCES}

[1]Gao Hong. Study on the core skills of British occupation education and training[D]. Hebei University,2004, pp.21-26.

[2]Shao Aiqun. British occupation development of core competencies and to our country occupation education [D]. Sichuan Normal University, 2009, pp.18-24.

[3]Liao Xiangxin Occupation education core skill curriculum research and development [D] Nanjing Normal University, 2007, pp.30-33.

[4]Huang Riqiang, Huang Yongming. Core skills -- a new hotspot in the British occupation education[J]. Study on comparative education, 2004(02), pp.68-71.
[5]Wu Jianshe. Integrated curriculum in higher vocational core skill of the theory and practice[J]. Higher engineering education research, 2004(03), pp.45-49. 